\title{
SEOS - EARSEL'S PROJECT ON SCIENCE EDUCATION THROUGH EARTH OBSERVATION FOR HIGH SCHOOLS
}

\author{
Rainer Reuter and the SEOS Project Team
}

Carl von Ossietzky University of Oldenburg, Institute of Physics D-26111 Oldenburg, Germany - rainer.reuter@uni-oldenburg.de

KEY WORDS: Science education, eLearning, remote sensing tutorials, earth observation

\begin{abstract}
:
SEOS is an initiative for using remote sensing in science education curricula in high schools funded under the $6^{\text {th }}$ Framework Programme of the European Commission (EC). Eleven partners from several European countries, in cooperation with the European Space Agency (ESA) and teachers from European high schools, created e-learning tutorials for science students in high schools. The tutorials cover many disciplines such as physics, biology, geography, mathematics and engineering, emphasising the interdisciplinary character of remote sensing. They are the core element of the SEOS Learning Management System, allowing teachers to create their own courses, to distribute already available or new worksheets to the students for homework and to collect the results. Forums are available for teachers, students and other users to exchange information and discuss topics relevant for their study.
\end{abstract}

\section{THE SEOS PROJECT}

The Project SEOS (Science Education through Earth Observation for High Schools), funded by the European Commission in 2007-2010 and coordinated by the European Association of Remote Sensing Laboratories (EARSeL, http://www.earsel.org), is an effort to enhance the sensibility of high school students towards their environment and encourage interest towards natural sciences (European Commission, 2004) with the help of remote sensing images of the Earth.

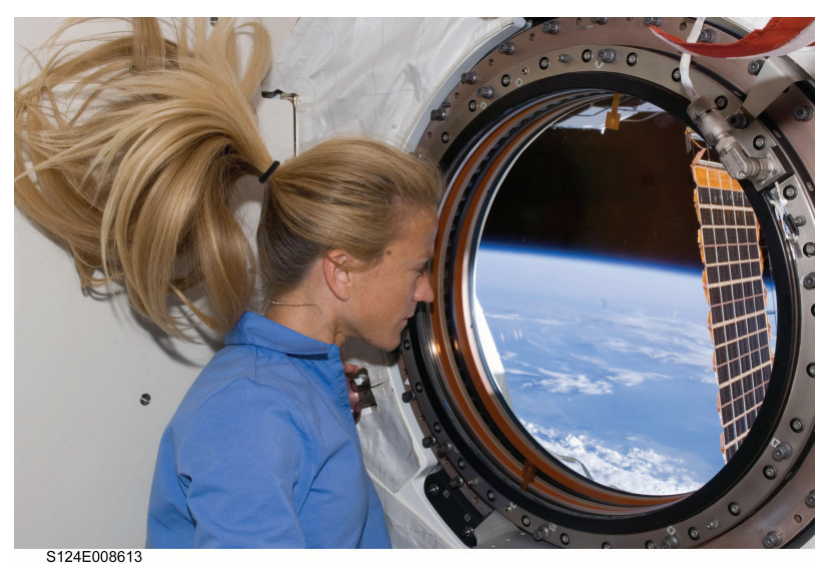

Figure 1: Astronaut Karen Nyberg looking at the blue planet while on board the International Space Station.

Courtesy: NASA/Johnson Space Center.

A consortium of EARSeL member laboratories, supported by the European Space Agency (ESA) as an observing member, worked together to realise fifteen learning tutorials. Teachers from partner high schools in Belgium, UK, Germany and Denmark evaluated the tutorials and tested them in the classroom. The tutorials cover a wide array of topics ranging from remote sensing of the atmosphere, ocean and land surface to current environmental issues such as pollution, natural disasters, land use change and climate change (global warming).
The project covers many disciplines such as physics, biology, geography, mathematics and engineering, emphasising the interdisciplinary character of remote sensing. Young users are encouraged to transpose their own personal observations into a global perspective. They should be able to understand and apply effective working methods which enable them to gather necessary information and interpret these correctly, In this way they gain insight into the nature of scientific enquiry, and develop their investigative skills. Ultimately, the aim of Project SEOS is to convey basic methods of scientific research, which is a key qualification in the field of modern science education.

Integrating earth observation into science education in high schools provides students with a basis for using environmental monitoring techniques in their subsequent working life. For this reason and aside from being used in schools, the tutorials also meet the demands of training courses for the users of the Global Monitoring for Environment and Security (GMES; http://www.gmes.info) services of ESA and the European Union. Moreover, UNESCO uses the SEOS training materials for educational purposes in selected developing countries, thus extending the benefits of this project to an even larger audience.

\section{THE TUTORIALS}

Based on real examples, the tutorials use remote sensing images and data to involve students in different aspects of current environmental research and monitoring. They demonstrate how information from satellites can be directly relevant to everyday life conditions and emphasise the importance of awareness of the environment.

The tutorials cover a broad range of topics, from daily weather data to long-term climatic conditions, land use and land cover changes, marine pollution and environmental hazards, ocean currents, coral reefs and coastal water quality, natural and cultural heritage and conservation, time series analysis, classification and modelling, and climate change, to name but a few. Connections between different topics are made clear, and links make it possible for teachers and students to follow their own route through the lessons according to their own interests. 
The tutorial $A$ World of Images features selected satellite images showing different facets of the Earth which enable young students to appreciate the beauty of our home planet as seen from space. A virtual spaceship takes the user to a flight through the Milky Way galaxy, passes by the planets of our solar system and finally reaches the planet Earth which opens up into a mosaic of colourful images. A click on an image opens up explanatory texts with links to related tutorial pages. Intriguing questions at the end of the text can be dealt with during lessons or given as homework.

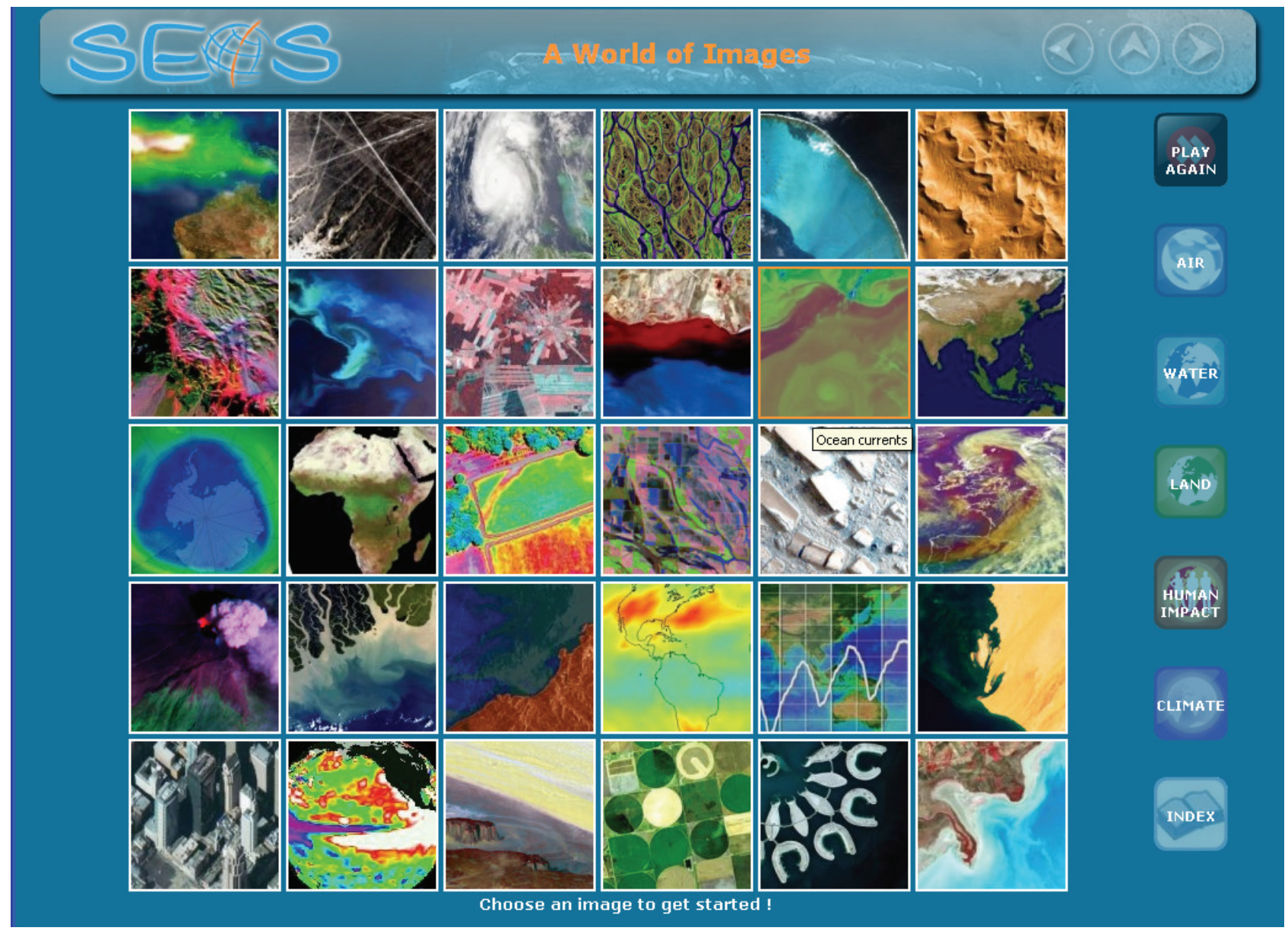

Figure 2: A mosaic of satellite images in the tutorial $A$ World of Images, showing an overview of all themes

For geography and biology education, there are tutorials dealing with the topics

- Conservation and Protection of World Heritage,

- Coral Reefs,

- Land Use and Land Use Change,

- Remote Sensing and Geo-information Technologies in Agriculture,

- Natural Resources Management, and

- Ocean Colour in the Coastal Zone.

The latter contains cross references to physics for which there are tutorials dealing with

- Understanding Spectra from the Earth,

- Marine Pollution,

- Ocean Currents,

- Laser Remote Sensing, and

- $\quad$ Satellite Navigation with GPS.
For mathematics education there are tutorials entitled

- 3-D Models Based upon Stereoscopic Satellite Data,

- $\quad$ Time Series Analysis,

- Classification Algorithms and Methods, and

- Modelling of Environmental Processes.

The tutorial entitled Introduction to Remote Sensing provides an introductory overview on all aspects of Earth observation using aircraft and satellites.

The tutorials use the method of Enquiry-based Learning (European Commission, 2007). This is also supported by worksheets highlighting an interesting scenario in the environment followed by questions or tasks which can be solved when studying the web-based tutorials. Advanced information on a more complex level is available through links to supplementary pages, which is particularly relevant with tutorials that are used in physics and mathematics classes, or even in university courses. 


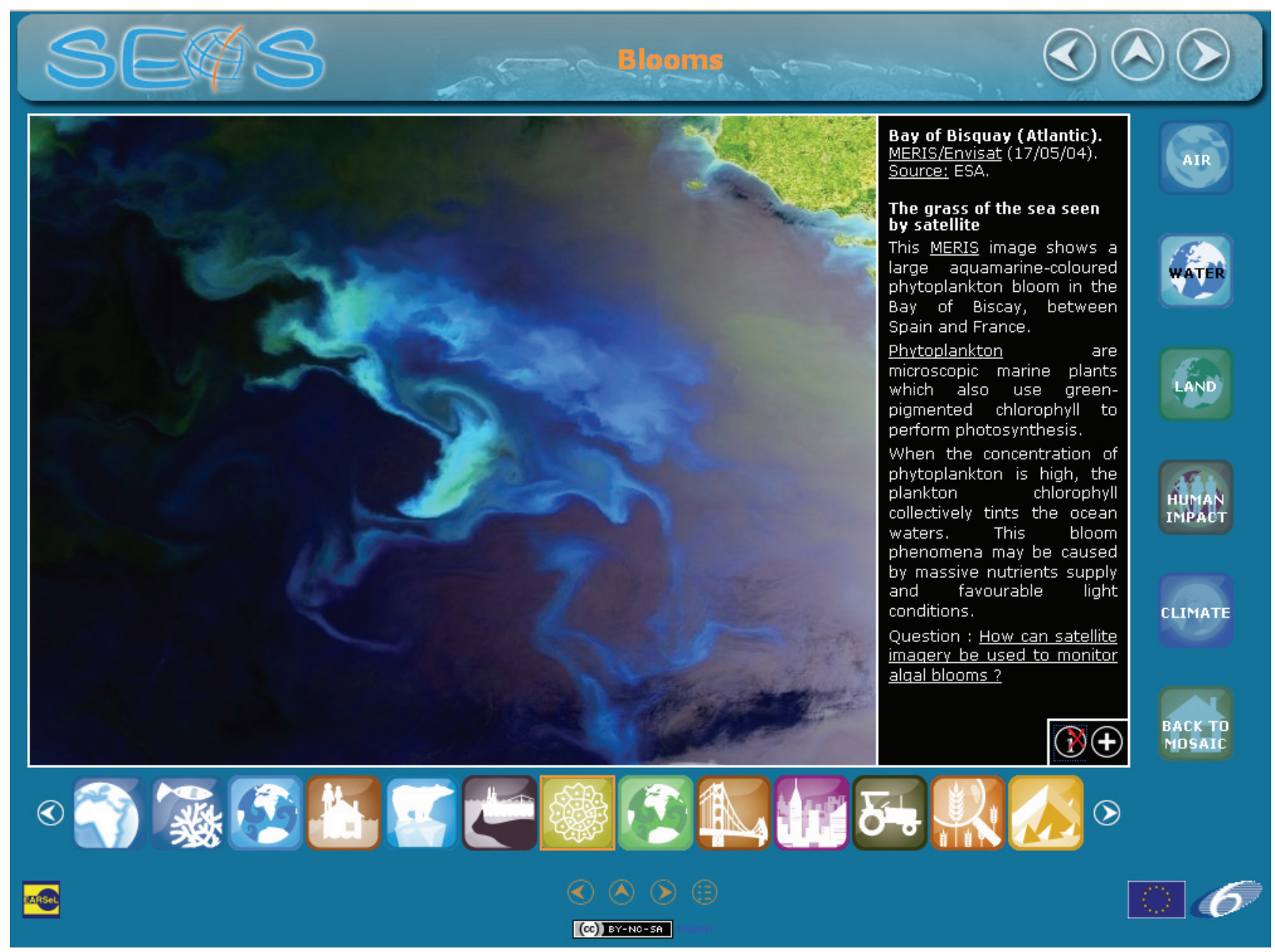

Figure 3: A webpage on marine phytoplankton blooms in the tutorial A World of Images, showing a bloom in the Bay of Bisquay. Explanations in the black window (activated with a click at the 'i' symbol) include links to other more detailed SEOS pages. The full resolution image can be accessed with a click on '+'. Navigational arrows allow to flip pages. Logos lead to other topics of Earth observation..
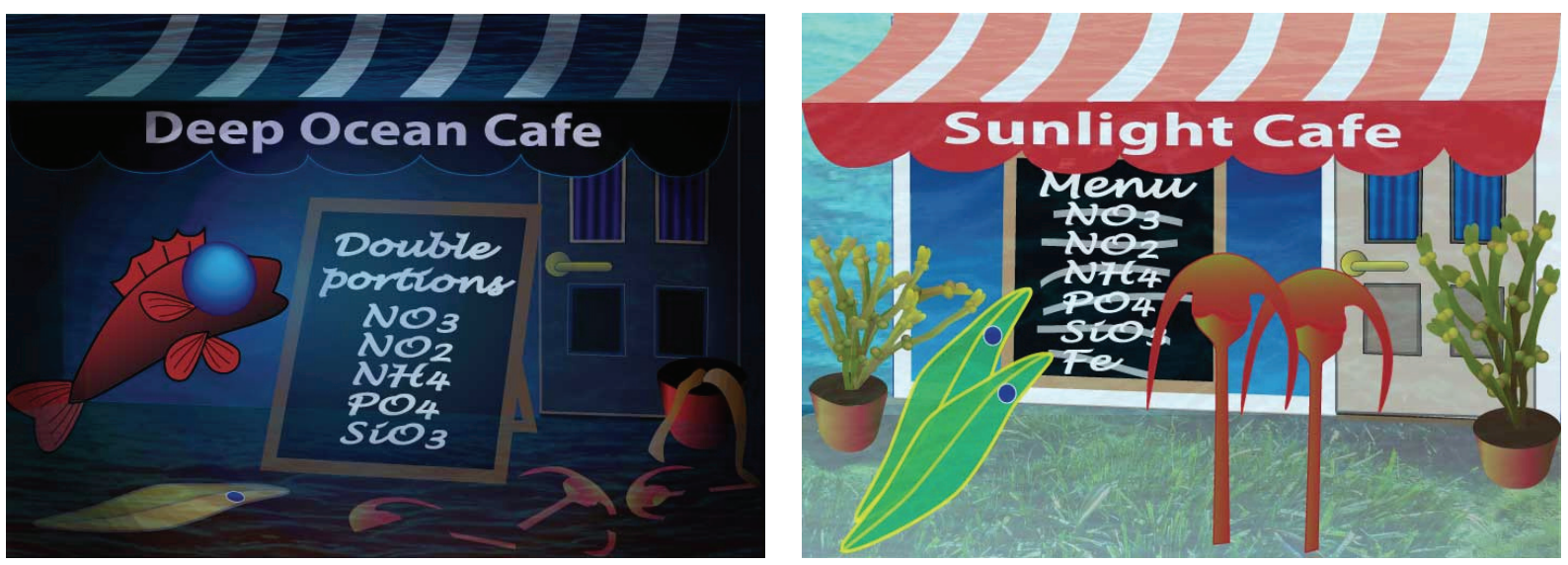

Figure 3: Illustrations from the tutorial Marine Currents, depicting the distribution of nutrients in seawater

which is a limiting factor of phytoplankton growth. Nutrients are abundant in the deep oceans where sunlight is scarce (left). In the near-surface layers this is the other way around (right). The role of wind and ocean currents and physics as a driving factor of biological processes is explained in the tutorial. Courtesy: National Oceanographic Laboratory, Southampton, UK

\section{THE LEARNING MANAGEMENT SYSTEM}

The tutorials are the core element of the SEOS Learning Management System (http://lms.seos-project.eu), allowing teachers to create their own courses, to distribute already available or new worksheets to the students for homework and to collect the results. Forums are available for teachers, students and other (e.g. GMES) users to exchange information 
and opinions, and to discuss topics relevant for their study. Together with the partner high schools, a strong emphasis is placed on proper didactical methods for conveying the contents of the tutorials. The learning material is applicable for different teaching methods and group work/projects. Worksheets containing questions about the topics encourage students to learn and explore independently.

Learning Management System and tutorials are available with open access in English, German, French, Greek, Dutch and Arabic language, and shall be translated in Spanish and Czech in the near future.

\section{ACKNOWLEDGEMENTS}

The SEOS project was financially supported by the European Commission in its $6^{\text {th }}$ Framework Programme under Contract SIP5-CT-2006-030849. The support of Dr. Francesco Sarti, Scientific Coordinator of the Education and Training Activities at ESA/ESRIN is gratefully acknowledged.

\section{REFERENCES}

European Commission, 2004. Europe Needs More Scientists. Report by the High Level Group on Increasing Human Resources for Science and Technology in Europe. $215 \mathrm{pp}$ http://ec.europa.eu/research/conferences/2004/sciprof/pdf/final_en. pdf

European Commission, 2007. Science Education NOW: A Renewed Pedagogy for the Future of Europe. 29 pp.

http://ec.europa.eu/research/science-society/document_library/ pdf_06/report-rocard-on-science-education_en.pdf, 